\title{
IV
}

\section{MUSEUS DE CIÊNCIAS: UMA PONTE ENTRE A \\ CIÊNCIA E A SUA NATUREZA*}

\author{
Thaís Balada Castilho \\ Maria Betânia Moreira Carvalho Silva
}

\section{Introdução}

Vislumbrar uma formação educacional transcendente aos muros da escola já é uma realidade ancorada por parte dos profissionais da educação. Os processos educativos podem ocorrer em uma observação investigativa nas ruas de uma cidade, na contemplação da produção de sinos de uma fábrica ou, ainda, em uma visita ao museu. A educação tem buscado diversos ambientes e espaços dialogando com múltiplas linguagens, a fim de dinamizá-la e enriquecê-la.

Os museus de Ciências e espaços científico-culturais, enquanto instituições potenciais para a popularização das temáticas científicas, são exemplos de locais que a educação tem explorado. Consolidou-se, ainda, "como uma das mais representativas instituições educativas fora da escola que visa o aprimoramento da educação científica e tecnológica" (FRANCO-AVELLANEDA, 2013, p. 25).

Com tantas potencialidades, as exposições desses espaços vão, cada vez mais, diversificando sua linguagem para que um maior número de visitantes seja atingido e, também, para que se amplie a valorização das diversas manifestações históricas e culturais, de modo que corroborem para que o sentimento de pertença e identidade à humanidade e ao universo sejam aumentados nos visitantes dos museus de Ciências. Dessa forma, os sentidos de história, cultura, identidade, ambiente e educação ganham novas dimensões.

*DOI - 10.29388/978-65-86678-24-6-0-f.77-92 
Com o objetivo de um canal mais direto e aberto, tem-se buscado que os visitantes dos museus de Ciências agucem seus olhares e consigam contemplar as linguagens e os discursos presentes em suas exposições. Marandino (2008, p. 16) coloca que "é preciso que o visitante seja ativo e engajado intelectualmente nas ações que realiza no museu e que as visitas promovam situações de diálogo entre o público e, deste, com os mediadores".

A abordagem da extensão educativa dos museus de Ciências está condicionada com o tempo, o espaço e a importância dos aparatos (MARANDINO, 2005). Dessa forma, o processo de codificação se dá pelo contato com estes aparatos e em como estes significam aos visitantes. Castilho, Sousa e Ovigli (2018, p. 146) colocam que:

A interação sociocultural permite a introspecção cognitiva capaz de redefinir o objeto descoberto e desenvolver uma compreensão dos temas tratados. Essa interação tem uma condição única que é alguém que queira ou precise saber. Assim, aprender em um museu de ciências, por exemplo, leva a quem aprende uma visão em várias dimensões e transforma a aprendizagem em um processo prazeroso que, até certo ponto, pode não ser reconhecido como aprendizagem pelos visitantes.

Pensar em questões socioculturais dentro do contexto científico é uma das designações da Natureza da Ciência a qual, apesar de ser bastante discutida no meio acadêmico e em documentos oficiais relacionados à educação, ainda não está totalmente delimitada. Lederman (2007) coloca que as bases para as discussões gerais que tangem a $\mathrm{Na}$ tureza da Ciência submergem de um arcabouço de saberes sobre as bases epistemológicas, filosóficas, históricas e culturais.

Sob essa perspectiva, iniciamos a discussão que travaremos durante todo este capítulo, orbitando em torno de como a Natureza da Ciência e os Museus de Ciências podem se retroalimentar no contexto da educação científica. Ainda, como o suporte mútuo entre estas duas 
temáticas pode diminuir o espaço entre a Ciência e suas construções e a sociedade, de maneira geral.

\section{Natureza da Ciência}

Discutir a construção, a organização e o estabelecimento do conhecimento científico é uma das diretrizes da Natureza da Ciência $(\mathrm{NdC})$. Além desses aspectos, inclui “[...] desde questões internas, tais como método científico e relação entre experimento e teoria, até outras externas, como a influência de elementos sociais, culturais, religiosos e políticos na aceitação ou rejeição de ideias científicas" (MOURA, 2014, p. 36).

A definição acima não é um harmônico, já que a ciência é um empreendimento humano e complexo e, como tal, chegar a um nível de consenso filosófico não é uma tarefa trivial. Para Matthews (1995, p. 195) "ensinar ciência como um solilóquio no qual a ciência fala sozinha e evolui apenas pela autocritica é empobrecer a disciplina".

Apresentar uma visão consensual de $\mathrm{NdC}$ vem sendo a busca de vários grupos. Algumas dessas pesquisas geraram listas para atender a uma consonância pragmática "em torno de determinados aspectos válidos para se pensar a inserção da temática $\mathrm{NdC}$ nas escolas” (MARTINS; RYDER, 2014, p. 3). A visão consensual tem como proposta o entendimento "do caráter provisório do conhecimento, da inexistência de um método único e rígido, a existência de vieses teóricos na observação e experimentação, as influências históricas, sociais e culturais" (MARTINS, 2015, p. 714).

Ryder (2002) coloca que aspectos conexos à sociologia da ciência são pouco apresentados dentro da visão consensual, não absorvendo de modo profundo a construção da ciência. Reconhecer que os fatores sócio-históricos são questões de influência, o contexto científico não tem sido problema para grande parte dos pesquisadores, porém o grau de importância desses fatores tende a ser minimizado, quando 
não excluído, ao se pensar nos fatores relativos estritamente aos dados da pesquisa.

Sendo a ciência configurada como dinâmica, descrevê-la sob um leque de regras não é tarefa fácil. Além disso, ao depositá-la em “caixinhas pré-moldadas", perdemos detalhes característicos e não reprodutíveis que são únicos dentro de cada processo científico, o que mostra que a visão consensual da ciência pode não ser a melhor alternativa para a NdC. Irzik e Nola (2011, p. 3, tradução nossa) afirmam que:

A visão consensual retrata uma imagem muito monolítica da Ciência e é cega em relação às diferenças entre as disciplinas científicas. Por exemplo, astronomia e cosmologia são muito diferentes, digamos, da química por elas não serem disciplinas experimentais. De forma relacionada, sob a visão consensual, a natureza da Ciência parece ser fixa e atemporal.

Os mesmos autores consideram que, embora existam características comuns a todas, somente essas características não podem definir a ciência como única. "Desta forma, teremos uma semelhança familiar com relação aos objetivos da ciência de acordo com diferentes interpretações ou posições filosóficas" (IRZIK; NOLA, 2011, p. 8, tradução nossa).

As semelhanças que unem as ciências, de acordo com Irzik e Nola (2011), são: atividades (observar, experimentar, matematização e práticas materiais), objetivos e valores (finalidades diferentes de acordo com as várias interpretações filosóficas), metodologias e produtos. Assim, pode ser que determinado ramo da ciência tenha semelhança nas regras metodológicas que utiliza quando comparada a um outro ramo científico, mas seus objetivos e produtos são tão diferentes que não podem ser considerados a mesma ciência. Para concluir a defesa deste conceito que chamam de semelhança familiar, os autores afirmam que essa abordagem: 
É mais abrangente do que a visão de consenso, capta a natureza dinâmica e aberta da ciência e tece as relações entre suas categorias e os vários elementos que se enquadram nelas de forma integrada, no entanto, é simples o suficiente para ser efetivamente útil para dar aos alunos uma boa ideia sobre a natureza rica da ciência. Ela permite que o professor caracterize a ciência em poucas palavras: a ciência é um sistema cognitivo ou padrão de prática e pensamento que envolve tais e tais atividades; valoriza e visa tal e tal; produz assim e assim usando tais e tais metodologias e regras metodológicas (IRZIK; NOLA, 2011, p. 15, tradução nossa).

Usar uma abordagem que permita entender quem na verdade são as pessoas que produzem ciência aproxima a todos desta área e permite uma discussão de tópicos científicos com menos estranhamento. Com o mesmo pensamento, Martins e Ryder (2014, p. 2) colocam que:

Uma compreensão mais profunda de como a ciência funciona, como o conhecimento científico é produzido, validado e comunicado, assim como a própria natureza desse conhecimento, no que se refere às suas particularidades epistemológicas, tem sido vista como algo a ser buscado e com valor para a educação científica.

Para que a ciência possa ter espaço dentro das discussões contextualizadas socialmente, é necessário bem mais que dominar sua reprodução mais comum, ou seja, decorar fórmulas, repetir experimentos, identificar símbolos e classificar estruturas. É necessário entender como a ciência influencia nas decisões de cunho social e em sua reciprocidade. Para tal, é importante que a sociedade possa oferecer discussões que permitam aos cidadãos uma educação pautada no desenvolvimento de habilidades que culminem em uma formação social, de convivência com o outro.

A educação científica visa construir meios para que o cidadão, levando em conta sua compreensão de mundo e de identidade, compreenda a ciência e, com base nela, tome decisões sobre questões que 
envolvam o meio ambiente, interesses, conflitos ou qualquer ato em que a ciência esteja envolvida. Moul e colaboradores (2016), considerando os estudos de Cachapuz (2011), propõem o desenvolvimento de:

[...] capacidades e valores, de modo que seja capaz de formar cidadãos alfabetizados cientificamente, que reflitam sobre seu papel na tomada de decisões responsáveis. Logo, é de suma importância o fornecimento de uma educação que afaste os discentes da construção de aspectos deformados da ciência, visando uma independência intelectual, como também participação no exercício da cidadania e democracia (CACHAPUZ et al., 2011 apud MOUL et al., 2016, p. 3867).

Assim, os autores reconhecem a importância da escola, enquanto propulsora da difusão da ciência como construção e prática humana. Contudo, a utilização de outros espaços constrói uma educação científica mais audaz e universal. As atividades construídas nos museus de ciências revelam-se motivadoras, abordando dinâmicas e recursos que dificilmente são de fácil reprodução em outros ambientes. Dessa forma, é possível entender de forma mais íntima e lúdica a construção do conhecimento científico.

\section{Os Museus de Ciências}

Os Museus de Ciências e centros tecnológicos atuais são decorrentes dos chamados "gabinetes de curiosidades", locais voltados para as práticas científicas e humanistas que tiveram grande destaque durante o século XVII, época de ascensão do pensamento positivista e do modelo científico pautado no pensamento racional e instrumental de Descartes, Galileu e Newton (JAPIASSU, 1982).

Uma das primeiras entidades dessa categoria foi o de Alexandria, antiga capital do Egito, que foi fundado por Ptolomeu, sedento por conhecimento e intelectualidade, após a divisão do império de Alexandre, o Grande, devido à sua morte (FLOWER, 2010). A compo- 
sição do Museu de Alexandria tinha aspectos que se diferem dos atuais museus, uma vez que se destinavam à nobreza, com a finalidade de promover debates, aulas, pesquisas e cópias de documentos, relacionados aos mais diversos temas.

As coleções e exposições daquela época refletiam a construção de pensamento, ou seja, as bases da sociedade burguesa em desenvolvimento, o evolucionismo e o desenvolvimento de instrumentos (SOUZA, 2009). Nota-se que no iniciar das atividades o museu detinha um ambiente elitista e função meramente contemplativa e passiva aos que o visitavam, sendo que a função educativa, a acessibilidade e a compreensibilidade de suas exposições eram destinadas a poucos.

Nos séculos seguintes, especialmente no XX, em países europeus e nos Estados Unidos, iniciou-se uma preocupação com o público destes locais e em como eles interagiam com o espaço. Desta forma, os museus de Ciências abriram espaços e programações a diferentes faixas etárias e públicos, e procuraram diferentes estratégias para a interação com o visitante. Toda essa visão foi possibilitada por uma nova concepção destinada aos museus de Ciências, a de que este estava como um bem a serviço da comunidade e que também detinha uma responsabilidade educativa (CAMBRE, 2017).

Com o reconhecimento da Ciência Moderna e de seus avanços, museus de Ciências serviram como ferramenta de intensificação e demonstração de seus empreendimentos, o que demarcou sua importância. Surgiu a necessidade da construção de estratégias para falar sobre ciências com todos os públicos, já que os museus foram ganhando espaços e visibilidade em diversos locais. Havia, ainda, a preocupação da articulação entre Ciências e sociedade. Todos estas novas responsabilidades e apreensões construíram uma nova visão de museu, que se afasta do contemplativo e busca a interação.

No século XXI os museus de Ciências caminharam no sentido de serem cada vez mais interativos, de modo a propiciar aos visitantes diferentes aprendizagens e a interação real das ciências com o cotidiano. Cambre (2017, p.111, tradução nossa) analisa que: 
Um museu de ciências hoje não seria um lugar em que se encontra grandes vitrines repletas de objetos apenas para observar. Em contraste, seria um espaço em que se pode observar e encontrar objetos, mas também se pode perguntar, participar, questionar, dialogar. Hoje a opinião do visitante, a valorização da sua experiência, assim como a preocupação para chegar a todos os cidadãos é a parte de prioridade dos museus de Ciências.

Contextualizando todo esse movimento no âmbito brasileiro, percebe-se um crescimento dos museus de Ciências a partir de 2007, com o Plano de Ação do Ministério de Ciência e Tecnologia 20072010, que tinha como objetivo popularizar a ciência, aproximá-la da sociedade e propiciar diferentes espaços de interação e conhecimento em todas as regiões do país (CONTIER, 2009).

Consoante a este pensamento, Valente e colaboradores (2005) analisam a funcionalidade dos museus de Ciências e apontam que esses podem ser enxergados por diferentes concepções da técnica e das ciências, destacando que um ponto importante a ser discutido é a interação promovida com o público. Dessa forma, nota-se que esse novo olhar diz respeito ao diálogo que se tem estabelecido entre a ciência e a sociedade, atribuindo aos museus de Ciências novas dimensões e importância para a sociedade.

Esse viés de interação, participação e diálogo dos visitantes com as exposições presentes nos museus de Ciências demonstra um novo olhar para este espaço, que repercute diretamente no olhar para as Ciências. Isso contextualiza a ciência, auxilia para a visibilidade dos aspectos sociais, culturais e políticos aos quais as ciências estão envolvidas.

Os museus de Ciências humanizam a Ciência, possibilitam a visualização no tempo-espaço histórico de cada construção, as percepções da $\mathrm{NdC}$ e sua construção, o que nos permite refletir sobre a humanidade. Não apenas sobre as contribuições científicas e tecnológicas, mas também sobre os impactos socioambientais provocados pelo desenvolvimento das ciências. Trata-se da literacia científica, de uma 
compreensão de mundo que é construída, reformulada, em movimento e consonância com todo o contexto sócio histórico que se pretende incentivar.

Cambre (2017), ao se posicionar afirmando que as exposições tendem a propiciar muito além do que a educação formal, aponta que a interação com os museus de Ciências liga-se diretamente às dimensões filosóficas conceitual, humana (concepção cognitiva, emocional e social), espacial, temporal, museográfica e educacional, demonstrando a riqueza e a diferentes possibilidades das visitas aos museus de Ciências.

\section{Aproximação entre Natureza da Ciência e museus de Ciên- cias}

Diversas pesquisas no âmbito acadêmico vêm evidenciando a constante propagação de ideias ingênuas sobre a construção da ciência, seus trabalhadores e a relação entre ciência e sociedade (GILPÉREZ et al., 2001; DRIVER et al., 1996; LEDERMAN, 1992; AIKENHEAD; RYAN; DESAURLS, 1989). Em resumo, essas imagens ingênuas estão relacionadas ao que caracterizamos como senso comum e descontextualizado da realidade.

Construir uma abordagem que permita uma aproximação entre a construção da ciência, o desenvolvimento social e a educação provoca aproximação e permite uma discussão de tópicos científicos com menos estranhamento. Com o mesmo pensamento, Martins e Ryder (2014, p. 2) colocam que:

Uma compreensão mais profunda de como a ciência funciona, como o conhecimento científico é produzido, validado e comunicado, assim como a própria natureza desse conhecimento, no que se refere às suas particularidades epistemológicas, tem sido vista como algo a ser buscado e com valor para a educação científica. 
Pensando no conceito de ciências como um grande e complexo empreendimento, estabelecemos quatro pontos de sutura entre os campos científicos, sendo eles (i) atividades, (ii) objetivos e valores, (iii) metodologias e (iv) produtos. Então, como uma exposição em um museu de ciências pode ajudar os visitantes a entenderem a construção da ciência de modo a fugir de uma visão ingênua e de senso comum sobre este empreendimento humano?

Diante da contemplação de figuras e imagens de um cientista conhecido por uma teoria, Isaac Newton, por exemplo (tido como o pai da ciência moderna e como o "descobridor" da teoria da gravidade), é possível discutir outros aspectos importantes, como a valorização do conhecimento, da sociedade, do patrimônio, dos diferentes momentos sócio-históricos, da cultura, dentre outros. Uma teoria é fruto apenas da genialidade de um cientista, como Isaac Newton, ou será que outras pessoas contribuem para a construção? Como são vistas as atividades dos cientistas? Quais as influências que eles carregam? Será que são realmente neutros em suas conclusões? Será que a ciência só ocorre dentro dos laboratórios?

Existe o axioma de que a Ciência e seus trabalhadores são neu tros, ou seja, livres das influências mundanas e sem questões ideológicas que possam, de alguma forma, interferir na construção da ciência. Levar ao centro da discussão questões da NdC colabora para o esclarecimento desta questão mostrando que todos os cientistas são influenciados pelo seu contexto social, "são seres humanos comuns, por isso cometem erros, utilizam de suas crenças e expectativas para elaborar e legitimar suas ideias, têm qualidades e defeitos" (MOURA, 2014, p. 4).

Todas essas proposições sobre o fazer científico podem ser discutidas em uma exposição de museu de Ciências, de modo a construir uma relação estreita entre museu e educação científica. Desta forma pode ficar evidente a existência de campos científicos diversos e, como tal, trabalhadores e atividades diversas. Também é necessário frisar a colaboração humana necessária para que os conceitos se tornem em- 
preendimentos científicos. Apesar de parecer um trabalho solitário, a ciência é fruto do trabalho colaborativo e contínuo.

Com as exposições presentes nos museus, torna-se possível discutir a construção do conhecimento científico, dos métodos e entender que nem todas as áreas da ciência necessitam da linearidade do método científico positivista proposto por René Descartes (15961650).

Um experimento científico também pode ser estudado como um produto científico. Com o estabelecimento das ideias de Newton, uma nova forma de entender e interagir com os fenômenos naturais foi construída e se expandiu para todos os aspectos da sociedade e culminou no Iluminismo ${ }^{1}$, que mais tarde foi um dos fatores da eclosão da Revolução Industrial. O símbolo dessa Revolução, a máquina a vapor, é amplamente mostrada e divulgada em exposições científicas. É possível construir analogias parecidas entre contexto científico e social também com a expansão da eletricidade e do uso dos computadores.

Utilizar os museus de Ciências para essas discussões têm o objetivo de humanizar a ciência, buscando contextualizar e problematizar sua construção. Assim, os museus de Ciências tornam-se espaços privilegiados por permitir que a partir da interação das exposições com o público, os visitantes possam apreender as diferentes dimensões que contemplam as ciências.

O que tem chamado a atenção de pesquisadores é a necessária preparação dos professores e mediadores dos museus de Ciências para proporem a contextualização histórica, cultural e social das exposições a fim de estimular a leitura científica. Contier (2009) chama a atenção, também, que o conhecimento científico influencia diretamente na vida da sociedade, e muitas vezes esse impacto passa despercebido. Assim, os atores da mediação da sociedade e das ciências têm que reverberar e problematizar essas questões. Dessa forma, entende-se a necessidade

\footnotetext{
${ }^{1}$ Conceitua-se o Iluminismo como um "[...] movimento intelectual europeu do século XVIII, que reuniu os maiores pensadores e filósofos da época em diversos países" (LOPES, 2011, p.142). Buscava valorizar o conhecimento, a racionalidade e a razão em detrimento de explicações sobrenaturais para os fenômenos e acontecimentos.
} 
de "[...] trazer à luz debates tanto da perspectiva de que a ciência é socialmente construída, ou seja, que a sociedade interfere, sim, em seus processos, quanto sobre as consequências socioambientais do de desenvolvimento científico e tecnológico" (CONTIER, 2009, p. 12).

Para tanto, é necessário pensar em uma leitura científica e a presencialidade dos construtos apresentados nas exposições em âmbito de cotidiano social, enriquecendo, dinamizando e mostrando-a viva pois, assim, ela se poderá mostrar-se interessante, atrativa e estudada com mais profundidade.

\section{Considerações Finais}

Como já dito, a ciência é um empreendimento social complexo! Para o seu entendimento é necessário alcançar o contexto histórico e social do surgimento de cada uma das suas contribuições superando, assim, visões relativas ao senso comum sobre a construção do conhecimento científico.

A interface que se revela rica entre Natureza da Ciência e os museus de Ciências estão retroalimentadas na construção de uma ciência. É vinculada à história, à memória, às vivências, às práticas humanas que são construídas, reconstruídas e podem/devem ser questionadas. Os museus de Ciências se apropriam dos modelos e das construções científicas transmitindo, a partir das exposições, compreensões de mundo que contemplam as Ciências da Natureza, ao passo que estas têm no museu um espaço que difunde e possibilita o aproximar-se da sociedade com essa visão de Ciência, que é produto da ação humana, intencional e valiosa, contudo limitada.

Apropriar-se deste espaço para promover uma reflexão sobre a linguagem e produções científicas é, de fato, salutar. A alfabetização científica, tão discutida atualmente, encontra nos museus de Ciências um facilitador para que este processo ocorra, à medida que estimula e fomenta reflexões, interatividade e questionamentos sobre as Ciências, dentro de um percurso social, histórico, cultural e geográfico. 
Sabe-se que, no bojo dessa discussão, estão as questões organizacionais das exposições e suas preocupações com o financiamento e a rentabilidade das exposições e o fluxo de visitantes. Ainda, a dificuldade de planejamento das visitações escolares e a própria condição cultural de pouca visitação alocada à sociedade brasileira. Todas essas questões renderiam outro capítulo.

Todavia, acreditamos na confluência e entroncamento dessas temáticas para a construção de uma visão de uma Ciência viva, em movimento, que é construída e reconstruída na dinâmica da sociedade.

\section{Referências}

AIKENHEAD, G. S.; RYAN, A. G.; DESAURLS, J. Monitoring student views on STS topics. Paper presented at the annual meeting of the National Association for Research in Science Teaching, San Francisco, 1989.

CAMBRE, M. Centros y museos interactivos de ciencia en America Latina. In: MASSARANI, L. et al. (Orgs.). Aproximaciones a la investigacion en divulgacíon de la ciencia en America Latina a partir de sus articulos academicos. Rio de Janeiro: Fiocruz, 2017. p. 107-137.

CASTILHO, T. B.; SOUSA, A. R.; OVIGLI, D. F. B. Educação Científica nos museus de Ciências: a importância das diversas linguagens presentes nas exposições. Evidência, Araxá, v. 14, n. 14, p. 139-148, 2018.

CONTIER, D. Relações entre ciência, tecnologia e sociedade em museus de Ciências de ciências. 2009. 154 p. Dissertação (Mestrado em Educação) - Faculdade de Educação, Universidade de São Paulo, São Paulo, 2009. Disponível em: $<$ http://www.geenf.fe.usp.br/conteudo/arquivo/dissertacao djanacontier.pdf. $>$ Acesso em: 10 out. 2018.

DRIVER, R. H.; LEACH, J.; MILLAR, R.; SCOTT, P. Young peoples's images of science. Buckingham: Open University Press, 1996.

FRANCO-AVELLANEDA, P. M. Ensamblar museus de Ciências de ciência e tecnologias: compreensões educativas a partir de três estudos de caso. Tese 
(Doutorado em Educação Científica e Tecnológica) - Universidade Federal de Santa Catarina. Florianópolis, SC, 2013.

FLOWER, D. A. A Biblioteca de Alexandria: as histórias da maior biblioteca da Antiguidade. Tradução de Otacílio Nunes e Valter Ponte. São Paulo, Nova Alexandria, 2010.

GIL-PÉREZ, D.; MONTORO, I. F.; ALÍS, J. C.; CACHAPUZ, A., PRAIA, J. Para uma imagem não deformada do trabalho científico. Ciência \& Educação. v. 7, n. 2, p. 125-153, 2001.

IRZIK, G; NOLA, R. A Family resemblace approach to the nature of Science for Science education. Science \& Education, v. 20, p.591-607, 2011.

JAPIASSU, H. O nascimento e a morte das ciências humanas. Rio de Janeiro: Francisco Alves, 1982.

LEDERMAN, N. G. Student's and teache's conceptions of the nature of Science: a review of the research. Journal of Research in scienceTeaching. v. 29, n. 4, p. 331-359, 1992.

. Nature of science: Past, presente and future. In: ABELL, S,;

Handbook of research in Science education. New York: Routledge, 2007.

LOPES, F. R. de A. Iluminismo ou iluminismos? Revista Vernáculo, n. 2, p.133-161, $1^{\circ}$ sem./2011.

MARANDINO, M. A pesquisa educacional e a produção dos saberes nos museus de Ciências de ciência. História, Ciências, Saúde - Manguinhos, Rio de Janeiro, v. 12, n. suplemento, p. 16181, 2005.

Educação em museus de Ciências: a mediação em foco. São Paulo: Grupo de Estudo e Pesquisa em Educação Não-formal e Divulgação em Ciências, 2008.

MARTINS, A. F. P.; RYDER, J. Há realmente um consenso acerca da natureza da ciência no ensino de ciência? XV Encontro de Pesquisa em Ensino de Física - ENPEC. Maresias, 2014, Anais..., Maresias, ENPEC, 2014.

MARTINS, A. F. P. Natureza da ciência no ensino de ciências: uma proposta baseada em "temas" e "questões". Caderno Brasileiro de Ensino de Física, v. 32, n. 3, p. 703- 737, 2015. 
MATTHEWS, M. R. História, filosofia e ensino de ciências: a tendência atual de reaproximação. Caderno de Ensino de Física, v. 12, n. 3, p. 164-214, dez. 1995.

MOUL, R. A. T. M.; ARAUJO, M. R. P.; SILVA, T. K. F.; MARQUES, T. P. S.; SILVA, R. N. M. A natureza da ciência e suas contribuições para o ensino: como estudantes da educação básica veem os cientistas. Revista da Sbenbio, n. 9, p.3866-3875, jul. 2016.

MOURA. B. A. O que é natureza da Ciência e qual sua relação com a História e Filosofia da Ciência? Revista Brasileira de História da Ciência, Rio de Janeiro, v. 7, n. 1, p. 32-46, 2014.

RYDER, J. School science education for citizenship: strategies for teaching about the epistemology of Science. Journal of Curriculum Studies, v. 34, n. 6, p. 637-658, 2002.

SOUZA, D. M. V. Museus de Ciências da ciência, divulgação científica e informação: reflexões acerca de ideologia e memória. Perspectiva em Ciências da Informação, v. 14, n. 2, p. 1555-168, 2009.

VALENTE, M. E., CAZELLI, S. e ALVES, F.: Museus, ciência e educação: novos desafios. História, Ciências, Saúde - Manguinhos, vol. 12 (suplemento), p. 183-203, 2005. 
